\title{
EFL Teachers' Practice and Learners Preferences for Oral Error Corrective Feedback in EFL Speaking Class
}

\author{
Dereje Asfaw Bulbula \\ Instructor, Department of English Language and Literature, College of Social Sciences and Humanities, Bonga \\ University, Ethiopia P.O. Box: 334, Bonga \\ Damtew Bulbula Areda, \\ Instructor, Department of English Language and Literature, College of Social Sciences and Humanities, Ambo \\ University, Ethiopia P.O. Box: 19, Ambo
}

\begin{abstract}
By using descriptive research design with quantitative and qualitative data gathering method, this study attempted to asses EFL (English as a Foreign Language) teachers practice of giving oral error corrective feedback and learners preferences for oral error correction. In doing so, data were gathered from grade 11 students and their English language teachers. Three English languages teachers were included for observation and interview by using comprehensive sampling technique and eight students were also selected for interview by using purposive sampling technique. Each teacher was observed three times and a total of nine classroom observations were made on four classes while EFL teachers teach speaking skills, and the data were recorded for three hundred sixty minutes. To gather quantitative data, questionnaires consists of four major parts were used. On the other hand data from classroom observations, teachers' and students' interview were analyzed qualitatively. Findings of the study revealed that EFL teachers always give oral corrective feedback on learners' oral error. Teachers were found using explicit correction strategies most of the time. Learners prefer to be corrected by their teacher always and teachers were also found to be the dominant corrector of learners' oral error. This indicated that EFL teachers' actual classroom practice is divorced with some scholarly suggested pedagogical consideration.
\end{abstract}

Keywords: Oral error, corrective feedback, practice, preferences

DOI: $10.7176 /$ JLLL/66-01

Publication date:March $31^{\text {st }} 2020$

\section{Introduction}

\subsection{Background of the Study}

The goal of second language or foreign language teaching is to develop communicative competence and to enable learners to use language accurately and fluently for communicative purposes (Spada, 2011). Language teaching could apply a form/accuracy focused instruction and meaning/fluency instruction. A lot of scholars in the area of foreign and second language deny the importance of form focused instruction and favored meaning focused instruction for a number of reasons. But language teaching and learning is all about the accuracy and fluency because language learning mainly focuses on the mastery of four language skills. It calls for well-designed teaching procedures, active involvement of teachers and students, good feedback provision and good techniques of teaching to enable students at different level to make use target language appropriately (Pawlak, 2014).

As Pawlak (2014) points out one type of feedback provided in EFL setting is oral error corrective feedback and this feedback type is perceived as an isolated phenomenon that just happens in the classroom because learners are bound to produce inaccurate language forms and teachers have to deal with them in one way or another, as it is part of their job.

Soler (2015) citing Katayama (2007) asserts that EFL and ESL (English as a Second Language) students may have different opinions and preferences towards how to have their errors corrected in the language classroom. Knowing these preferences may help teachers captivate their students. According to Katayama (2007), differences in the learning styles of the students will affect the learning environment by either supporting or inhibiting their intentional cognition and active engagement. Thus, students will feel more motivated by doing things they like and prefer. In the classroom, teachers can use this information as a tool to motivate students and help them improve their learning process.

According to Margolis (2010) good oral feedback strategies can boost student motivation, advance language learning, increase student perception of instructional effectiveness, build confidence, and create a satisfying learning experience. Most of the research conducted in this area abroad showed that learners have a strong desire of receiving corrective feedback. For instance; to mention few of them a research by Cathcart \& Olsen (1976), Oladejo (1993), Yao (2000), Schulze (2001) and Lee, (2004) shows that students wanted more error correction but teacher fears to give more feedback for learners.

However, teachers have been found to adopt ambiguous and unsystematic corrective feedback techniques or approaches. Sometimes they accept errors for fear of interrupting the communicative flow, and at other times they 
correct the same errors (Allwright, 1975 \& Chaudron et al., 1977). Researchers like; Lyster and Ranta (1997) concluded that the teachers' correction targeted on a wide range of learners error types leading to an overwhelming linguistic data in the form of corrective feedback, which means an overload for learners' cognitive capacities. Although there are contentious natures of error correction practice, according to different scholars and researchers, successful language learning can take place when both teachers and learners have a common understanding on their practices and preferences of error correction process. Therefore, to help the learners achieve the necessary language competence, appropriate feedback and correction should be given to them.

\subsection{Statement of The problem}

In the case of Ethiopia where English language is taught as a foreign language the existence of errors in learners' language is something inevitable and unavoidable issue. Thus in different educational institutions like high schools, the students are engaged in a number of interactive practices during speaking skill lessons and oral production activities. Consequently, they are expected to give their response for different exercise and oral practices. In fact students' ill formed utterances have to be commented by their classroom teachers or peers. The current study intends to assess the teachers' practices of giving oral error corrective feedback provision that they carry out during spoken English class in EFL classroom.

Additionally, Asassfeh (2013) puts forward four noteworthy observations about research in error correction. They are: 1) most of the research about error correction has been conducted in ESL context than EFL context, 2) there are no conclusive results about the usefulness or otherwise of error correction, 3) it is not clear whether direct feedback is more effective or indirect one, and 4) whether teachers should be selective in provision of feedback or address all errors by learners. Therefore taking in to consideration what Asassfeh (2013) has observed the researcher of this study was initiated to take part on conducting study on this area in EFL context.

On this regard, there are a number of foreign researches conducted in this area; for instance, Lyster and Ranta (1997) conducted a study on teachers' feedback type and students' uptake. The participants in their study were young ESL learners and they found recasts were the most commonly used corrective feedback by the teachers, but it [recast] were the least likely to lead to successful uptake. As to their finding the most successful type of feedback resulting in students' repair was elicitation. Therefore from their finding it is more likely possible to say that teachers' oral error correction practice is not in line with the learners' preference. This means elicitation is the techniques that learners prefer while corrected their ill formed utterance and it lead them to successful reformulation but the teachers practice as to the finding of Lyster and Ranta (1997) was by far different from the way learners need to be corrected.

Therefore their research ignores to conduct study on teachers' practice and learners' preference of oral error correction together but simply focus on teachers' feedback type. In order to bring successful teaching and learning of language at general level and FL in specific level conducting a study on teachers' oral error corrective feedback practice and learners' preference for correction is very useful. As a result of this the current study focuses on the teachers' actual practice of oral error corrective feedback provision and learners preference for oral error corrective feedback in the EFL classroom.

Moreover in this regard, as to the researchers knowledge, few local studies have been conducted to examine error treatment and feedback provision. To mention few of them Animaw (2011) studied, an exploratory case study of the interplay between teachers' beliefs, classroom practices, and rationales of oral corrective feedback. In his study he found that trainees did not have a firm theoretical ground on which they based their actions. Rather, they reacted to their students' errors based on what they intuitively felt was right or they treated errors the way their own teachers treated their errors when they were students themselves. They also tended to avoid correcting their students' errors; possibly due to lack of mastery of the language they are supposed to teach. Moreover Kasaye (2006) studied oral feedback provision during plasma satellite lesson where teachers obviously face constraints of time and found that the teachers always provide correct responses. Besides, Legesse (2008) shows that grade 11 teachers focus on provision of accuracy based correction and feedback and mainly teachers emphasize on the type of feedback and mother tongue influence is the cause for students.

The preceding locally conducted researches mainly focused only on the teachers' perception of error correction and types of error, but they totally ignored the teachers' practices and students' preferences for oral error correction. Language learning in its best is meant to be meaningfully learned well by the active involvement of both teachers and students.

The present study however is different from the aforementioned studies as it focuses on the teachers' practices of oral (spoken) error correction and students' preference for the correction by investigating the actual classroom practices in EFL Speaking classrooms. Moreover, the current study's methodology, setting, and research questions are different from the aforementioned studies. Therefore, this study will mainly attempt to assess teachers' practices and learners' preference for oral error correction. Having this aim in mind, the current researcher raised the following basic research questions:

1. How does EFL teachers' give oral corrective feedback in EFL speaking classes? 
2. On what type of error does English language teachers' mainly give emphasis when providing correction to the learners' oral errors?

3. What are the students' preferences for oral corrective feedback in EFL speaking class? And

4. Is there any match/mismatch between the teachers' practice and learners' preferences towards oral corrective feedback?

\section{Review of Literature}

\subsection{Corrective Feedback}

Badma (2015) citing Mackey, Gass \& McDonough, (2000) stated that feedback is used to express an opinion or a reaction to another person's performance. Furthermore, it could be used to praise achievement or to point out an error or a mistake (Marzano, 2003). Moreover feedback is a chain in the continuous system of teaching, learning and it makes the whole system function as an upward spiral. It helps both the teacher and students to know about their teaching and learning respectively. It has been increasingly recognized that teachers' feedback is an important factor influencing students learning (Kluger \& DeNisi, 1996 as cited in Badma, 2015). Lack of clear feedback about the line of reasoning students are supposed to be following leaves them confused and eventually they lose interest (Wragg, 2001 as cited in Badma, 2015). Thus, feedback has immense power to encourage students to work hard and indicate what they need to focus on when they are having difficulty. Moreover, Lightbown (2000) has defined corrective feedback as an indication for the students that their use of the target language is incorrect in using it Corrective feedback includes both explicit and implicit feedback.

\subsection{Oral/Verbal Feedback}

Badma (2015) points out that during lessons, teachers use a lot of oral or verbal feedback to let students know how they are doing and also to transition from one section to another. Short expressions such as 'Good', 'Great!' or 'Well done!' can be used to praise students for correct answers. Rather than telling students directly that they are incorrect, it is better to ask them to try again or reconsider their answers. The goal is to elicit the correct answer from the class and students should not be afraid of being wrong so keep your reactions positive (Chumun, 2002 as cited in Badma, 2015). Lyster and Ranta (2013) identified the following oral corrective feedback types which occur during a lesson.

\subsection{Preferences and Practice of Oral Error Corrective Feedback}

Individual students' preference for feedback/correction/ varies considerably. Some students want praise, others may see it unimportant, some like a response on their ideas, others demand to have all their errors to be corrected, some use teacher comments, others ignore it ( Hyland 2003). Despite the students expectation of error treatment seems difficult, it is vital to consider the language proficiency level of the learner, their belief and the context of language learning.

In this regard, Horwitz (1988) notes that teachers need to know learners' beliefs about language learning in order to foster more effective learning strategies in their students because severe disappointment caused by a mismatch between students' expectations about language learning and the realities they encounter in the classroom can impede language acquisition. Few researchers in this field have investigated teachers' and students' perceptions of error correction and found mismatches between them. For example, Schulz (1996:2001) concluded that students' attitudes toward grammar instruction and error correction were more favorable than their teachers' attitudes; that is, learners want more error correction. Thus, when their instructional expectations are not met, their motivation can be negatively affected, and they may question the credibility of the teacher.

\section{Methodology}

\subsection{Research Design}

The main objective of this study is to assess how oral error corrections are practiced by English language teachers and learners preference for oral error corrective feedback in EFL speaking classes. Taking in to consideration the nature and objective of the study, descriptive research design was employed in this study. This was because of the fact that this research design appears suitable for describing the actual classroom practices English language teachers carrying out when correcting learners' oral errors or when providing corrective feedback.

\subsection{Participants of the Study and Sampling Techniques}

This study was conducted in Oromia regional state, South West Shewa Zone, particularly at Yehibret Fire preparatory school located in Tullu Bollo town with particular reference to grade 11 students. The participants were grade 11 students and teachers of English language teaching the intended grade level. There were 256 students in Social and Natural science stream at Yehibret Fire grade 11 preparatory school, and three teachers teaching English language subject in this school.

From the total population of students and teachers, all teachers teaching English language subject in grade 11 
and also 64 students out of 256 students were participated in this study. In order to obtain the necessary data for the study, the researcher selected $64(25 \%)$ from $256(100 \%)$ students with the help of simple random sampling techniques; Therefore, both social Science A, B \& C and Natural Science D of grade 11 students were the participants in this study. In this case out of 64 (25\%) of sampled students, 16 each from section A, B \& C and D were selected so as to achieve the Sample and to fill questionnaires. 8 students from the total samples were also selected by using purposive sampling techniques for interview from the total sample. This means 2 students from each sampled number were selected based on their academic performance and engaged for interview. Because there were only three teachers who were assigned to teach English language for grade 11 students, the researcher took all of them using Comprehensive sampling technique and conducted an observation while they were teaching speaking skill in EFL classes and also interviewed them post classroom observations.

\subsection{Data Gathering Instruments}

The main aim of the study was to describe English language teachers practices of giving oral error corrective feedback and learners' preference for oral error correction in EFL speaking classroom. Error correction is a practical classroom activity to which teachers and students devote their time. Therefore, in order to get reliable and plausible data, questionnaire, classroom observations, and interview were used in this study for the data collection. The first two data gathering instruments was the major data gathering instruments in this study and the rest was the supplementary one. The questionnaire was used in this study in order to get the information that cannot be easily obtained through direct observation and interview. Moreover, According to Selinger and Shohamy (1989) a questionnaire is widely used in second language acquisition researches to seek information about certain conditions and practices, in particular to collect data on phenomena which are not easily observed, such as attitudes, self-concepts and preferences. Thus, this study employed a closed-ended questionnaire because Bailey (1994) notes that, closed-ended questionnaires are quicker to code up and analyze than word-based data. in order to generate responses amenable to statistical treatment and analysis, this study employed a closed-ended questionnaire that was organized in the form of 5 point rating-scale in which 5 represent always, 4 represent usually, 3 represent sometimes, 2 represent rarely and 1 represent never. Therefore the five rating scale that required participants to respond to each instructional item by choosing one from the alternatives.

The questionnaire contains five sections.. The questionnaires for the data collection have been adapted from Park (2010), Kazemi (2013), Tomczyk (2013) and Hussain et al (2016) with careful modification. The other data gathering instruments used in this study was classroom observation. Best and Kahn (2003) on the other hand point out that observation is the earliest and most frequently used data gathering tool and has also been the prevailing methods of inquiry to see what goes on in the class. Classroom observations were made when English language teachers teaching Speaking skill. These were done for three periods each in all teachers' classes. The data from classroom observations were gathered by two instruments. This was by audio-recorder and note taking form. A note taking form was adapted from Maaliskuu (2008) with slight modifications.

Moreover the other data gathering instruments used in this study was Interview. Interview, as the data collection instrument, enables to gather in depth information, free or flexible responses that would not be easy to obtain by other tools (Selinger \& Shohamy, 1989). Thus the interview questions for this study was prepared in such a way that it triangulate data that was obtained through questionnaire.

\subsection{Validity and Reliability of Data Gathering Instruments}

Haile (2015: 60) citing Cohen, et al (2000) asserts that Insuring validity and reliability in research tools all in all is quite difficult and looks impossible. It is strange to say threats to validity and reliability can ever be erased completely. Hence, "What is important to consider with regard to validity and reliability in a certain piece of research is paying due attention to decrease invalidity and unreliability and to increase validity and reliability throughout the research". Regarding the validity of data gathering instruments the researcher has used different techniques for insuring the validity of the instruments. This means before the actual use of the questionnaires the researcher has first pilot tested it on the population that are found on similar level with the target population. Moreover in order to insure the content and face validity of the questionnaires the researcher showed it [questionnaires] for different teachers and friends for comments. The questionnaire was given for a review to my advisor and as well as to two instructors in the department of English language and literature at Ambo University. Questionnaires were translated in to learners' mother tongue language which is in to Afaan Oromo.

On the other hand, in order to assure the internal consistency of the questionnaire, it was checked using the statistical package for social sciences (SPSS-Version 20.00) and the calculated Cronbach alpha revealed that: 
Table 1. Reliability results of the questionnaires Reliability Statistics

\begin{tabular}{|c|l|l|}
\hline Part of questionnaire & Number of Items Cronbach's Alpha \\
\hline 1 & 17 & .987 \\
\hline 2 & 4 & .976 \\
\hline 3 & 6 & .964 \\
\hline 4 & 4 & .923 \\
\hline
\end{tabular}

Therefore the internal consistency of all parts of the questionnaire items of this study is greater than 0.9 . Therefore according to the Cronbach Alpha decision the internal consistency of the questionnaire was found to be "Excellent" reliability.

\subsection{Data Collection Procedures}

First of all the researcher consulted the principal of the school for permission and then having permission from the principal office; the researcher contacted each sections and then Afaan Oromo version of the questionnaires were distributed to 64 [16 each from four sections] students. To avoid any kind of confusion and hesitation that may happen during data collection, the researcher clearly explained the objective of the study and direction of the items for sampled students. The day after collecting the filled questionnaires from students, 8 students were also selected from the sampled students by using purposive sampling method and semi structured interview were administered. Thirdly asking permission from the teachers for observation, classroom observations were held in the classes of all three English language teachers when they were teaching speaking skills. Finally, semi structured interview were also made with English language teachers too.

\subsection{Data Analysis Methods}

The data gathered through questionnaire, observation and interviews were analyzed both quantitatively and qualitatively. To analyze the response of the questionnaire the raw data was first entered in to computer to be analyzed using SPSS (statistical package for social science) version 20. Accordingly, the responses of the questionnaire were presented in the table form using frequency, percentage, mean scores, standard deviation and grand mean. The analyses of the questionnaire were made using mean score of items and grand means. This was done to reduce the bulkiness of the paper. In relation to this Kumar (1999) as cited in Tafere (2008:46) points out that "simple statistical measures such as percentages and means are helpful to reduce the volume of the data and make it easier to understand". In order to decide the extent at which the statements in the questionnaires are practiced by EFL teachers and preferred by learners, the five rating scale results decision were made based on the rating scale decision adapted from Anwar (2017). In which he classified as: Scales $<1.49=$ almost never (very slightly), 1.5-2.49= rarely (slightly), 2.5-3.49=Sometimes (moderately) $3.5-4.49=$ usually (highly) $>4.5=$ always (extremely). Therefore the mean value for data interpretations was made using the rating scale classification used by Anwar. Then the analysis of the questionnaire was made by using mean score and grand means. On the other hand classroom observation and interview were interpreted qualitatively.

\section{Results and Discussions}

The first objective of the study was to find out how teachers give oral corrective feedback in EFL speaking classroom. The practice of the teachers are presented in the following table as follows: 
Table 2. Students Response on How EFL Teachers give oral error corrective feedback

\begin{tabular}{|c|c|c|c|c|c|c|c|c|c|c|c|}
\hline Items & & & & Respo & ses & & & & & & Mean \\
\hline My English Language Teacher: & 5 & & 4 & & 3 & & 2 & & 1 & & \\
\hline & $\mathrm{F}$ & $\%$ & $\mathrm{~F}$ & $\%$ & $\mathrm{~F}$ & $\%$ & $\mathrm{~F}$ & $\%$ & $\mathrm{~F}$ & $\%$ & \\
\hline corrects my errors while I Speak & 34 & 54.93 & 16 & 25.90 & 10 & 16.12 & 1 & 1.7 & 1 & 1.7 & 4.31 \\
\hline $\begin{array}{llll}\text { corrects my oral errors } \\
\text { Selectively }\end{array}$ & 2 & 3.22 & 6 & 9.67 & 25 & 40.32 & 15 & 24.19 & 14 & 22.58 & 2.47 \\
\hline corrects all of my oral errors & 20 & 32.25 & 21 & 33.87 & 11 & 11.74 & 4 & 6.45 & 6 & 9.67 & 3.73 \\
\hline $\begin{array}{l}\text { Criticizes me while I make oral } \\
\text { error }\end{array}$ & 12 & 19.35 & 12 & 19.35 & 8 & 12.90 & 12 & 19.35 & 18 & 29 & 2.81 \\
\hline $\begin{array}{l}\text { gives me an explanation why the } \\
\text { oral error is made }\end{array}$ & 11 & 17.74 & 12 & 19.35 & 32 & 51.61 & 4 & 6.45 & 3 & 4.83 & 2.39 \\
\hline $\begin{array}{l}\text { Gives me direct praise i.e. (good, } \\
\text { very good, nice, etc.) }\end{array}$ & 6 & 9.67 & 32 & 51.61 & 12 & 19.35 & 2 & 3.22 & 10 & 16.12 & 3.35 \\
\hline $\begin{array}{l}\text { repeats my utterance with no } \\
\text { change of error or omission of } \\
\text { error }\end{array}$ & 3 & 4.83 & 3 & 4.83 & 4 & 6.45 & 7 & 11.29 & 45 & 72.6 & 1.58 \\
\hline $\begin{array}{l}\text { simply corrects me and continue } \\
\text { to other topics }\end{array}$ & 18 & 29.0 & 20 & 32.25 & 10 & 16.12 & 6 & 9.67 & 8 & 12.90 & 3.55 \\
\hline $\begin{array}{l}\text { adds emphasis to stress the } \\
\text { location of error and its correct } \\
\text { formulation }\end{array}$ & 3 & 4.83 & 3 & 4.83 & 12 & 19.35 & 18 & 29 & 26 & 41.93 & 2.02 \\
\hline $\begin{array}{l}\text { requests me to repeat utterance } \\
\text { with intent to have self- } \\
\text { correction }\end{array}$ & 2 & 3.22 & 4 & 6.45 & 9 & 14.51 & 27 & 43.54 & 20 & 32.25 & 2.00 \\
\hline $\begin{array}{l}\text { Interrupts my utterance } \\
\text { following my error before I have } \\
\text { completed my speech }\end{array}$ & 6 & 9.7 & 9 & 14.52 & 9 & 14.52 & 20 & 32.26 & 18 & 29.0 & 2.44 \\
\hline $\begin{array}{l}\text { further extends my error } \\
\text { without providing me correction }\end{array}$ & 1 & 1.61 & 3 & 4.83 & 9 & 14.52 & 9 & 14.52 & 40 & 64.52 & 1.79 \\
\hline $\begin{array}{l}\text { shows rejection by saying 'no', } \\
\text { uh, 'not exactly', etc. }\end{array}$ & 20 & 32.26 & 3 & 4.84 & 16 & 25.8 & 3 & 4.84 & 20 & 32.26 & 3.00 \\
\hline $\begin{array}{l}\text { corrects my spoken errors by } \\
\text { himself/herself }\end{array}$ & 29 & 46.8 & 19 & 30.64 & 10 & 16.12 & 2 & 3.22 & 2 & 3.22 & 4.15 \\
\hline $\begin{array}{l}\text { gives me the chance to correct } \\
\text { the errors by myself }\end{array}$ & 3 & 4.84 & 2 & 3.23 & 9 & 14.6 & 27 & 43.6 & 21 & 33.9 & 2.02 \\
\hline $\begin{array}{l}\text { asks other students to provide } \\
\text { me correction }\end{array}$ & 1 & 1.61 & 2 & 3.23 & 19 & 30.7 & 20 & 32.25 & 20 & 32.25 & 2.10 \\
\hline $\begin{array}{l}\text { Uses body language to indicate } \\
\text { my error }\end{array}$ & 3 & 4.84 & 4 & 6.45 & 12 & 19.54 & 25 & 40.32 & 18 & 29.0 & 2.18 \\
\hline
\end{tabular}

Scales $<1.49=$ almost never (very slightly), 1.5-2.49=rarely (slightly), $2.5-3.49=$ Sometimes (moderately) $3.5-$ $4.49=$

Usually (highly) $>4.5=$ always (extremely)

As it is shown in the table 2 above, the grand mean was 2.43 . The mean value is therefore inclined to rarely. This indicated that EFL teachers rarely employ the above techniques while providing Oral error correction.

The second research objective was to identify the type of error English language teachers' mainly give emphasis when providing correction to the learners' oral errors. The type of error EFL teachers gives focus while providing oral error corrective feedback is presented on the following table as follows: 
Table 3. Students' response on the types of error teachers give emphasis

\begin{tabular}{|c|c|c|c|c|c|c|c|c|c|c|c|}
\hline \multirow{3}{*}{$\begin{array}{l}\text { Items } \\
\text { When my English } \\
\text { language teacher provide } \\
\text { me oral feedback S/he } \\
\text { focuses on: }\end{array}$} & \multicolumn{10}{|c|}{ Responses } & \multirow[b]{3}{*}{ Mean } \\
\hline & 5 & & 4 & & 3 & & 2 & & 1 & & \\
\hline & $\mathrm{F}$ & $\%$ & $\mathrm{~F}$ & $\%$ & $\mathrm{~F}$ & $\%$ & $\mathrm{~F}$ & $\%$ & $\mathrm{~F}$ & $\%$ & \\
\hline grammar & 44 & 70.97 & 13 & 20.97 & 2 & 3.23 & 2 & 3.23 & 1 & 1.61 & 4.56 \\
\hline pronunciation & 7 & 11.29 & 6 & 9.68 & 21 & 33.87 & 17 & 27.41 & 11 & 17.74 & 2.66 \\
\hline $\begin{array}{l}\text { vocabulary (choice of } \\
\text { words) }\end{array}$ & 20 & 32.26 & 14 & 22.57 & 15 & 24.12 & 11 & 17.74 & 2 & 3.22 & 3.63 \\
\hline meaning & 1 & 1.61 & 1 & 1.61 & 1 & 1.61 & 18 & 24.12 & 40 & 32.25 & 1.44 \\
\hline
\end{tabular}

Scales $<1.49=$ almost never (very slightly), 1.5-2.49= rarely (slightly), $2.5-3.49=$ Sometimes (moderately) $3.5-$ $4.49=$ Usually (highly) $>4.5=$ always (extremely)

As it can be seen in the table three above, the grad mean of all the item is 3.12, and this mean values is inclined to sometimes; therefore, EFL teachers sometimes give correction on all types of language error. The highest mean value from the error type is 4.56 ; this indicated that teacher always give feedback for grammar error most dominantly than the other types of error.

The third research objective was to assess the students' preferences for oral error corrective feedback in EFL speaking class, and the student's preferences for oral error corrective feedback is presented on the following table.

Table 4. Student's preference response on the time of correction, and the corrector of their error

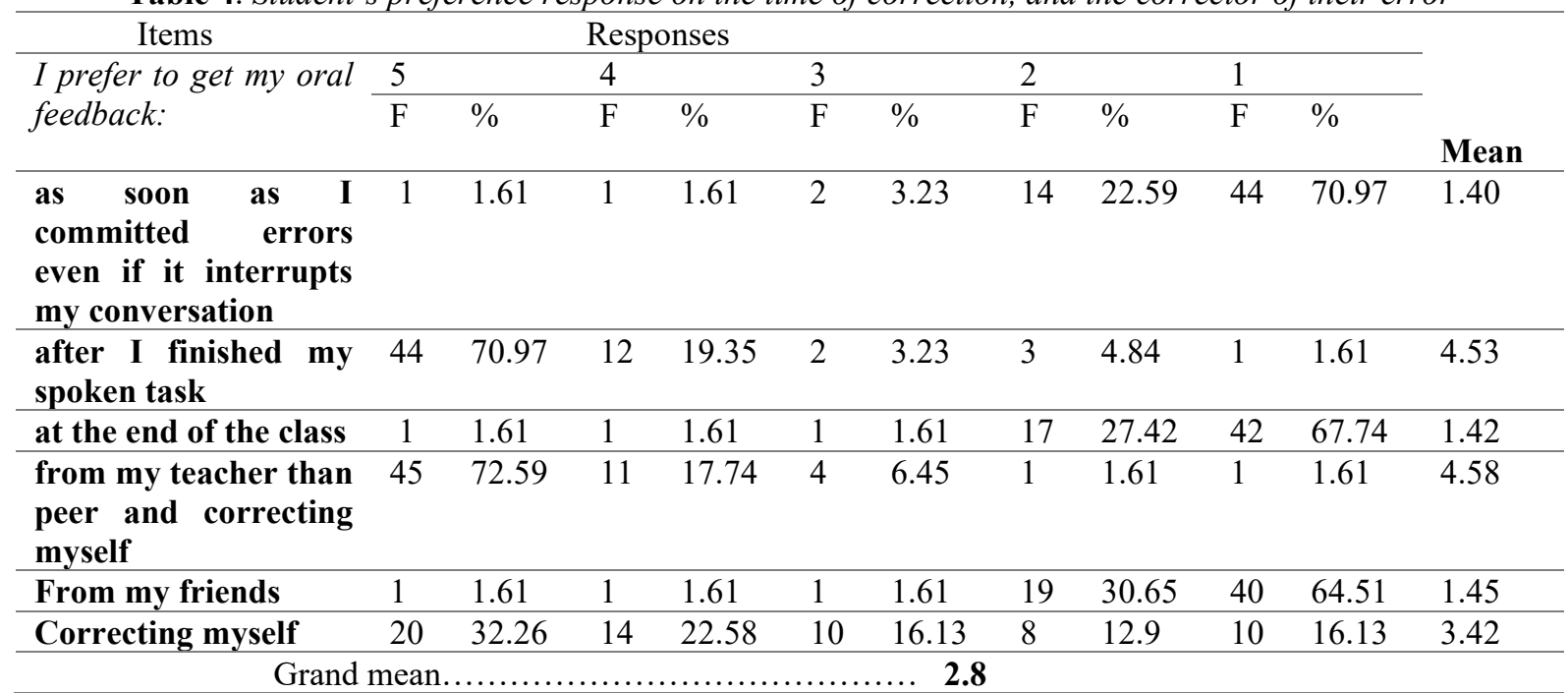

Scales $<1.49=$ almost never (very slightly), 1.5-2.49= rarely (slightly), $2.5-3.49=$ Sometimes (moderately) $3.5-$ $4.49=$ Usually (highly) $>4.5=$ always (extremely)

Table four illustrates that the grand mean score of all the items is 2.8 and it is inclined to sometimes. This indicates that students sometimes prefers to receive correction from the other agent and to correct themselves as well. When individually observed students never prefer to get their correction from their friends, at the end of the class and as soon as they committed the error. The mean value more than 4.5 indicates that students always prefer to be corrected by their teacher than their friends at after they finish their spoken task.

Table 5. Student's preference on type of error they would prefer to receive more correction Scales $<1.49=$ almost never (very slightly), 1.5-2.49= rarely (slightly), $2.5-3.49=$ Sometimes (moderately) $3.5-$

\begin{tabular}{|c|c|c|c|c|c|c|c|c|c|c|c|}
\hline Items & \multicolumn{10}{|c|}{ Responses } & \multirow[b]{3}{*}{ Mean } \\
\hline \multirow{2}{*}{$\begin{array}{l}\text { I prefer to get my oral feedback } \\
\text { more on: }\end{array}$} & \multicolumn{2}{|l|}{5} & \multicolumn{2}{|l|}{4} & \multicolumn{2}{|c|}{3} & \multicolumn{2}{|l|}{2} & \multicolumn{2}{|l|}{1} & \\
\hline & $\mathrm{F}$ & $\%$ & $\mathrm{~F}$ & $\%$ & $\mathrm{~F}$ & $\%$ & $\mathrm{~F}$ & $\%$ & $\mathrm{~F}$ & $\%$ & \\
\hline Grammar error & 44 & 70.96 & 15 & 24.19 & 2 & 3.22 & 1 & 1.61 & - & - & 4.63 \\
\hline $\begin{array}{l}\text { Pronunciation and intonation } \\
\text { error }\end{array}$ & 21 & 33.87 & 7 & 11.29 & 32 & 51.61 & 2 & 3.22 & - & - & 3.76 \\
\hline Vocabulary error & 18 & 29 & 23 & 37 & 10 & 16.12 & 7 & 11.29 & 4 & 6.45 & 3.71 \\
\hline meaning error & 9 & 14.51 & 12 & 19.35 & 17 & 27.41 & 17 & 27.41 & 7 & 11.29 & 2.98 \\
\hline Grand Mean. & & & . & 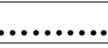 & 3.7 & & & & & & \\
\hline
\end{tabular}

$4.49=$ Usually (highly) $>4.5=$ always (extremely) 
The above table expresses student's preferences for the type of error they prefer to receive correction most dominantly; as a result the grand mean of all the item is 3.77. This is inclined to usually, and this indicated that learners usually prefer to receive correction on all the type of error they committed. The highest mean value of all the time is 4.63 and this shows that learners always prefer more correction than other type of error which is followed by pronunciation and intonation with the mean value of 3.76 .

The fourth research objective was determining the match or mismatch between the teachers' practice and learners' preferences. The analysis of match or mismatch is made on the type of error teachers give more attention, the type of error learners prefer to get more corrective feedback, the time at which the teacher give correction on learners ill formed utterance and as well as on the time of correction learners prefer to receive correction were the major focus of this section. As the data from students questionnaire reveals teachers always focus on grammar error with mean score of 4.58. Secondly teachers usually give focus on vocabulary error than other type of errors with 3.63 mean score, and similarly the data from classroom observation showed that teachers most of the time give focus on grammar error than other types of errors and they further confirmed it on their interview response. Whereas, the students' questionnaire, which deals about their preference, showed that, large number of learners responded that they always prefer to receive more correction on grammar error with mean score of 4.65 than other types of error. Students have a preference of usually receiving more correction on their vocabulary and pronunciation error. This is also substantiated by the interview question made with learners. Therefore there is a match between teachers practice and learners' preferences on the type of error get focused by teacher and preferred by learners.

The other one is the time of correction. Regarding this as the data from classroom observation, students questionnaires and as well as both teachers and students interview released, almost all the time correction were given at the end of the students speech but some teachers are observed while giving correction immediately as soon as errors are committed. Learners always (mean score of 4.53) prefer to be corrected at the end of their spoken tasks. Therefore in most teachers' class teachers practice and learners preference is matched but in some teacher class there is a mismatch between teachers' practice and learners' preferences on the time of correction. Learners also indicated they never prefer error correction at the end of the class and teachers were also not found in giving correction at the end of the class.

The other one is the corrector of an error. Regarding this the data obtained from learners' questionnaire, teachers classroom observation and both students and teachers' interview confirmed the agents who mainly take responsibility to give correction. Thus, teachers in learners' response to the questionnaire were found to be the dominant provider of correction. Whereas, learners in their response to questionnaire indicates that they always (4.58 mean score) prefer correction from their teachers. Thus in this case learners preference and teachers practice are found to be matched. This finding was also confirmed by learners' interview and teachers' interview too. Moreover learners indicates that they never (mean score of 1.45) prefer error correction from their friend [peer correction] but teachers were found in rarely ( 2.10 mean score) facilitating this means of correction. Furthermore students showed that they sometimes (3.42) prefer to correct error by themselves but teachers were found in rarely (2.02) facilitating this too. Therefore in this aspect there was a mismatch between teachers' practice and learners' preferences. (See table 2, 3, 4, 5).

\subsection{Discussion}

This study focused on exploring EFL teacher's practice of giving oral error corrective feedback and learners preferences for oral error correction. In order to achieve this objective the researcher has posed four basic research questions, so as to arrive at the finding questionnaire, classroom observations, and interviews were used as data gathering instruments.

The first research question formulated to elicit the method employed by English language teachers was, how does EFL teachers' give oral error corrective feedback in EFL speaking class? The analyzed data revealed that EFL teachers usually provide oral error corrective feedback or oral error correction in speaking classes. On this All Wright and Bailey (1991) points out that teacher need to provide learners with level appropriate corrective feedback that can promote their language learning. Therefore in connection to what All Wright and Bailey suggested English language all teachers were observed in giving corrections to learners' ill formed utterances. English language teachers do not always correct students' oral error selectively rather they rarely do so. Regarding this, Hendrickson (1978) as cited on Pawlak (2014) suggested that frequently occurring errors and errors that impair communication always should be selectively corrected; and various corrective feedback types should be used by teachers. Therefore in comparison to the suggestions of Hendrickson the finding of this study was not concurrent to what has been suggested by Hendrickson.

The second research question was identifying the type of error English language teachers give emphasis when providing corrections to the learners' oral errors? English language teachers during the oral error correction were found in giving high emphasis on grammar error than other type of error. Regarding this Tomczyk (2013) found that among the types of errors or out of the three main sorts of errors (grammatical, pronunciation and lexical ones), 
grammatical and pronunciation errors tend to be the most important and highly corrected by teachers and perceived by learners too. Therefore the research finding of this study is also concurrent to the finding of Tomczyk (ibid).

The third question was designed to know the students' preference regarding oral error correction in EFL speaking class? The analyzed data revealed that students prefer correction from their teachers than peer and correcting themselves, and they prefers receiving error corrections at the end of their spoken tasks always than immediate correction and delayed one. Moreover learners show their preference of receiving corrections to all types of error but among all type learners always highly prefer more correction on grammar error. On this Higgins (1987) states that Learners correct to each other in face-to-face interaction in a safe environment which helps students to protect their ego, increase their self-confidence and become more independent. Beside the importance of peer corrections stated by Higgins (1987) learners of this study do not prefer it and this finding is also not concurrent with what Higgins explained.

Finally, the fourth research question of this research was identifying the match or mismatch between the practice of teachers and the preference of learners. Regarding this Nunan (1987) points out that one of the basic serious blocks to learning is the mismatch between teacher and learner expectations about what should happen in the classroom. It is therefore identified that teachers practice of giving oral error correction and learners preferences in most cases: on the time of corrections, the corrector and as well as the type of error learners prefer high correction and teacher focus is matched.

\section{Conclusion}

The study aimed at exploring EFL Teachers' Practice and Learners Preferences for Oral Error Corrective Feedback in EFL Speaking Classes. The result revealed that EFL Teachers give oral error corrective feedback in EFL speaking classes most of the time and but they don't employ different techniques of giving oral error correction on students' ill formed utterances. Moreover praising and criticizing was employed by teachers as a means of corrective feedback provision to learners' oral error. Additionally English language teachers relays on limited correction techniques and practice very common techniques most of the time. Explicit strategies to oral error correction methods most of the time was used by English language teachers which does not have a potentiality of leading learners for repairing their error. Following explicit feedback provision techniques meta-linguistic feedback and elicitation techniques were less frequently employed by EFL teachers. Teachers do not always selectively correct learners' errors. Most of the time they involve themselves in correcting local errors and silly mistakes.

English language teachers mainly give emphasis on grammar error than other types of oral errors and Grammar and vocabulary errors are the most frequently committed types of error in EFL speaking classes respectively. Regarding when to correct the learners' error, learners always prefer to be corrected at the end of their speech and teachers were also appeared correcting learners' error at the end of their spoken tasks. Immediate and delayed corrections were not used by teachers and learners also do not prefer to receive correction at this time. EFL teachers are the most dominant corrector of learners' oral error and learners also highly prefer to be corrected by their teachers than peer and self-correction techniques. Self-correction and peer correction techniques are the neglected techniques of error correction by EFL teachers in speaking classes. This means teachers do not facilitate self-correction and peer correction in most cases.

Learners in EFL speaking class do not prefer peer correction for the reason that peer correction was appeared incorrect and learners feel that their friend may show superiority over them and as well as they don't prefer to receive corrections from the student found in their level. Teachers practice of giving correction and the method they employ to give corrective feedback was in line with the learners' preference in most cases.

Thus, the finding of this study made one recognition that EFL teachers' practice of giving oral error corrective feedback and learners' preferences on most cases matched together. However, this match is not in line with what literature under the pedagogical consideration of teachers practice has suggested in its most cases. This indicates that theoretical principles are distorted or limited both by teachers practice and learners' preferences. Giving oral error correction should not be the only duty of teachers. English language teachers must facilitate or encourage learners for self-correction and peer corrections so as to create cooperative environment for learners. The language teacher needs to be very vigilant in grasping the contextual complexities to make the correction work more meaningful, purposeful and effective (Sultana, 2009).

\section{References}

Abebaw (2007). "Teachers practice of giving written feedback and learners use". (Unpublished MA thesis): Debre Markos University.

Animaw Anteneh. (2011). "Oral corrective feedback: An exploratory case study of the Interplay Between Teachers" Beliefs, Classroom Practices, and Rationales".(Unpublished Doctoral Dissertation): Addis Ababa University.

Anwar Ahmed. (2017). Factors hindering the implementation of cooperative learning in Secondary school of Harari regional state, Ethiopia. International Journal of Research and Review 4 (12): 43-51. 
Asassfeh, S.M. (2013). Corrective feedback (CF) and English-Major EFL learners' ability in grammatical error detection and correction. English Language Teaching 6(8), 85-94.

Badima Belay. (2014). “EFL Teachers' Multiple Assessment Practices: the Case of three Government Secondary Schools in Addis Ababa". Unpublished MA Thesis: Addis Ababa University.

Cathcart, R. L., \& Olsen, J. E. W. B. (1976). Teachers' and students' preferences for correction of classroom conversation errors. In J. F. Fanselow \& R. H. Crymes (Eds.), On TESOL '76 (pp. 41-53). Washington D.C.: TESOL.

Haile Kassahun. (2015). "The English language needs of law students and designed ELAP syllabuses believed to meet the English language needs of law students at Debre Markos University (DMU”). (Unpublished Doctoral Dissertation): Addis Ababa University.

Horwitz, E. K. (1988). The beliefs about language learning of beginning university foreign language students. The Modern Language Journal 72: 283-294.

Kasaye Gutama. (2006) “An Exploration of the provision of oral feedback during satellite Plasma lesson". (Unpublished MA thesis): Addis Ababa University.

Katayama, A. (2007) Japanese EFL Students' Preferences toward Correction of Classroom Oral Errors. Volume 9. Issue 4 Articles 19. Retrieved on February 23- 2018 from http://www.asianefljournal.com/Dec 2007 ak.php.

Lyster, R., \& Ranta, L. (1997) Corrective feedback and learner uptake. Studies in Second Language Acquisition, 19, 37-66.

Lyster, R., \& Ranta, L. (2013). Counterpoint Piece: The Case for Variety in Corrective Feedback research. Studies in Second Language Acquisition, 35(1), 167-184. Retrieved from http://journals.cambridge.org/abstract_,doi: 10.1017/S027226311200071X.

Margolis, D. (2010). Handling Oral Error Feedback in Language Classroom. In Minne WITESOL Journal 27: 414.

Marzano, R. (2003). What works in schools: Translating research into action. Alexandria,VA: Association for Supervision \& Curriculum Development.

Nunan, D. 1993 "From Learning- Centeredness to Learner- Centeredness" In Applied Language Learning 4:1-18.

Oladejo, J. A. (1993). Error correction in ESL: Learners' preferences. TESL Canada Journal, 10(2), 71-89.

Park, H. S. (2010). Teachers' and Learners' Preferences for Error Correction. Sacramento: Californian State University.

Pawlak, M. (2014). Error Correction in the Foreign Language Classroom. Verlag Berlin Heidelberg: Adam Mickiewicz University.

Spada, N. (2011). Beyond form-focused instruction: Reflections on past, present and future research. Language Teaching 44: 225-236.

Schulz, R. A. (1996) Focus on form in the foreign language classroom: Students' and teacher views on error correction and the role of grammar. Foreign Language Annals, 29(3),343-364

Schulze, R. A. (2001). Cultural differences in student and teacher perceptions concerning the role of grammar instruction and corrective feedback: USA-Colombia. Modern Language Journal, 85(2), 244-258.

Selinger, H.W. and Shoamy, E. (1989). Second Language Research Method. Oxford: Oxford University Press.

Tafere Melaku. (2008). "The Status Of Pronunciation Teaching: Its Approach, Place And Teachers' Beliefs And Efficacy": Four Elementary Schools In Amhara Region In Focus. (Unpublished) MA thesis: Addis Ababa University. 